\title{
Impacts of localizing food system on farmers' livelihood resilience
}

\author{
P.S. Loo, F. Önal, K. Bax, M. Smairy and V. Surovets \\ Department of Geography, System Dynamics, University of Bergen, Norway
} Email:pei.loo@student.uib.no

\begin{abstract}
The concept of localizing food system gained traction in academic, policy, and development sectors in recent years, especially building resilience. The local council has a growing role in designing an efficient and equitable food system for community wellbeing. However, it is crucial to adopt fundamental solutions instead of short-term solutions of the problem. Also, an analysis should be conducted to understand both the positive and the unintended consequences of the proposed policies. To address this knowledge gap, the model is developed to explore policies' impact on building farmers' livelihood resilience in facing climate disturbance. The proposed combination of farmer market capacity expansion, farmer market organization marketing, setting up food and food box delivery policies deliver the best outcome in building resilience. The key messages of the project are, first, encourage a diversity of responses in building resilience; second, finding balance in managing limited resources for coping capacity versus future adaptative capacity; third, using group model building to build ownership of various stakeholders on the policy implementation. The potential next steps include quantifying resilience and diversifying types of consumers.
\end{abstract}

Keywords: Farmers' livelihood resilience, localizing food system, system dynamics 


\section{INTRODUCTION}

Local food systems are known as small-scale, localized products distributed to consumers through a shorter supply chain mechanism. In other words, localizing a food system means developing a food system specific to a community that addresses the needs of farmers and consumers. Localizing food system is growing popular in the policy course to pursue sustainable development. The local council plays a vital role in food system design, organization, policy, and implementation for community wellbeing. It is essential that the adoption of a local food agenda should be based on sound evidence. However, Deller, Lamie, and Stickel (2017) claim that current research on local and regional food networks reveals that much of this research currently lacks solid theoretical grounding and quantitative rigor. They further describe that earlier literature on local food systems is speculative and built on anecdotal accounts, and they urge that future research should incorporate greater rigor in the testing of suggested ideas. To address the knowledge gap, this project aims to explore the impacts of localizing food systems through system dynamics approach. The computational modelling and simulation tool can help the local council to test the likely impact of possible policies (what combination, at what scale, and with whom, for whom), weigh up the trade-offs of alternative policies, and act proactively and effectively.

\section{Simulation Modelling Technique}

In this study, a simulation model has been created using the system dynamics methodology, developed by Jay W. Forrester in 1950s, to study this complex system. System dynamics is one of the computational modelling techniques to frame, understand and tackle the complex problems. The model is a continuous time model includes dynamic stocks and flows consisting various internal feedback loops and time delays. A stock is the term for any entity that accumulates or depletes overtime represented by an integral equation where a flow is the rate of change in a stock overtime represented by a linear equation. Also, to show the dependency between elements of the model such as stocks, flows, and other variables, a link is used. This approach has been utilized to understand the nonlinear behaviour of the complex local food system in Australia over time.

\section{Problem Statement}

\section{Climate Disturbance}

Climate disturbance in South Australia are very tangible recent years. Droughts during the vegetation and heavy rains during the harvesting are the most challenging weather conditions for farmers. The severity of droughts and rains directly affects the crop production. Besides, climate disturbance jeopardizes also the logistic of products, flooding for instance. Perishable vegetables present a set of challenges that farmers of less perishable products do not face. In combination with adverse fluctuations in product prices, the vegetable farm profitability is unfavorable. Furthermore, not only farmers income is decreasing, the domino effect involves all the stakeholders in the food system. For example, a decreased production of healthy and affordable food leads to a fall in income of both farmers and consumers, and their quality of life.

\section{System Archetype: Fixes that Fail}

The system archetype: fixes that fail, is used to describe an unhealthy pattern in which mitigating symptoms prevail over finding fundamental solutions. In brief, short-term fixes that can only cope with the problem symptoms have triggered a series of side effects. The side effects undermine the fundamental solutions over time. Figure 1 illustrates fixes that fail on policies in alleviating impacts of climate disturbance on farmers' livelihood. During extreme climate disturbance, external intervention, primarily the government, compensates farmers for crop loss. When the government keeps doing this, by channeling most resources on the 'firefighting' approach, both government and farmers have no pressure or incentive to find solutions for farmers to be resilient

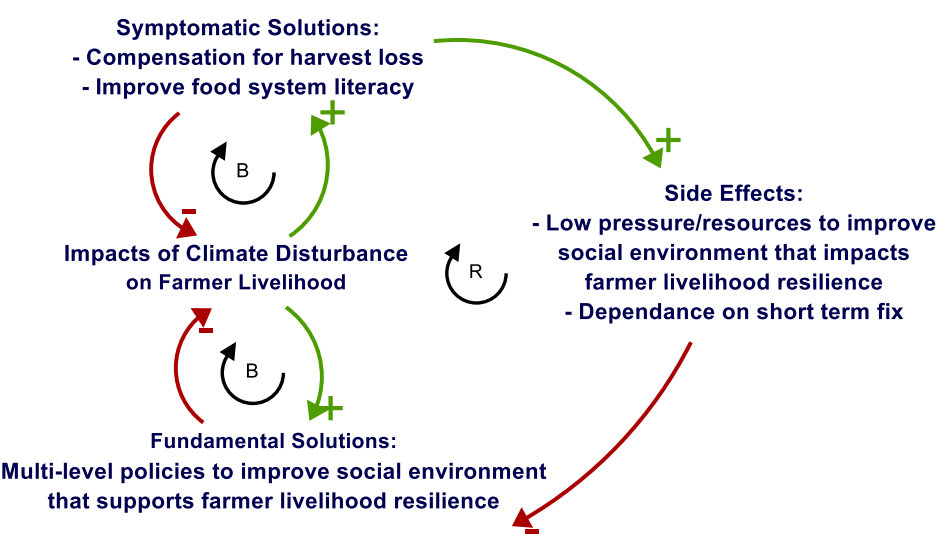

Figure 1. System Archetype: Fixes that Fail towards these shocks.

In addition, policy to increase food system literacy among farmers and consumers is gaining attention, where increase food system literacy will foster farmer resilience and increase consumer demand for local healthy foods. Nevertheless, it is debatable whether improve literacy alone can lead to behavior change. Having good food system literacy is not very helpful when the barriers to access or changing behavior is sky-high. This project does not object to policies for compensation loss or improving food system literacy; in fact, compensation can buy more time while developing resilience. It is, however, problematic to depend solely on short-term fixes. The 
project emphasizes improving the social environment that involves immediate physical infrastructure/services, social relationships, and power relations to achieve better farmers' livelihood resilience.

\section{What is Farmers' Livelihood Resilience?}

SURE-Farm study (2021) outlines how measures undertaken by the farming system in dealing with recurring shocks, evolve as the number of similar events increases. In case of severe droughts or flooding, immediate actions are undertaken to remove the shock; farmers get paid by the government for their losses. This is an immediate coping capacity through providing recovery resources. In the long run, increase of responsive capacity to adapt in avoiding exposure to future shocks is observed. Kangogo, Dentoni, and Bijman (2020) conceptualize the determinants of farm resilience, and propose mechanisms through which farmer entrepreneurship, membership in farmer organization, and farmer-buyer relationships may influence farmer adaptive capacity and thereby farm resilience.

\section{Recommended Policies}

How localizing food system impacts social environment that foster farmers' livelihood resilience in facing future climate disturbance? This model explores impacts of farmer markets, farmer market organization, food hub, and food box delivery policies on farmer adaptive capacity.

\section{Food hub}

typically operates to support wholesale customers like institutions (schools, hospitals, universities) that can purchase at scale.

The funding is proposed to set up food hub infrastructure and its operational cost. This policy enables more farmer to sell products with farmer organization negotiated prices. It aims to sustain farmers' livelihoods and meet consumer needs.

\section{Food box delivery}

is a box of variety of fresh/cooked food or set of meal kit that enable consumers to cook a simple meal in less than an hour.

The funding is proposed to set up food box delivery application/platform for farmers. This policy not only supporting consumers who are time-poor to have a quick and convenient way to enjoy healthy home-cooked meal, it also enables farmers to sell their products at a better price than wholesaler bulk price.

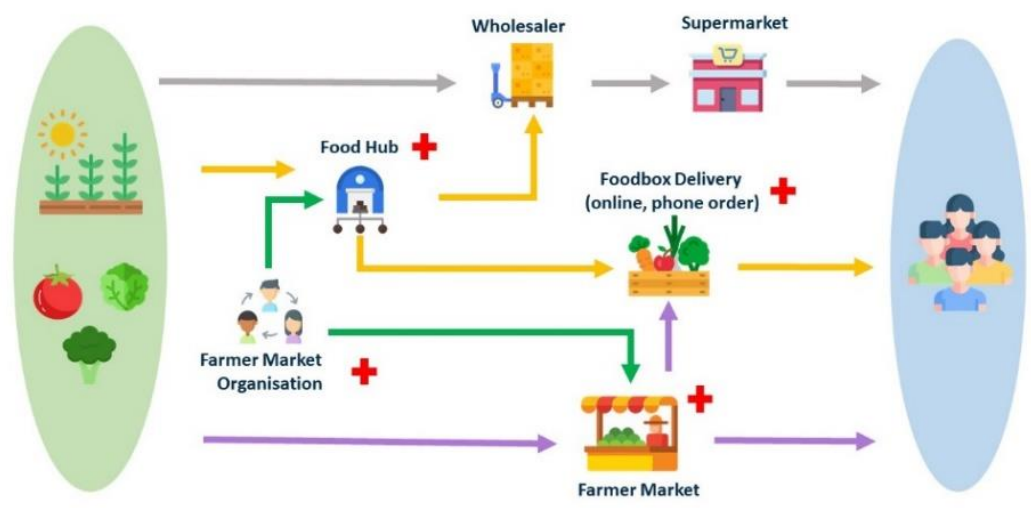

Figure 2. Farmer-consumer supply chain

\section{Farmer market organization}

typically to a voluntary collective action organization owned and controlled by farmers to pursue common interests, in this case, farmer market and food hub. Organization is crucial in providing the farmer with learning, legitimacy, governance, diffusion of innovation, and information necessary in adapting to changes. It also enables more farmers to sell products through food hub and farmer market.

The funding is proposed for marketing purpose to recruit more farmers to be members. The fund also includes incentive such as free first year membership fees.

\section{Farmer market}

is typically a fresh food market that operates regularly within a community, at a focal public location that provides a suitable environment for farmers to sell products directly to consumers. Farmers benefit from receiving higher prices for their products; having direct contact with consumers and hearing their feedbacks; building seller-buyer relationship.

The funding is proposed to expand capacity of farmer markets in areas with demand but lack of infrastructure; to support digitalization of farmer markets in collaboration of food box delivery; to improve farmers entrepreneur skill. 


\section{MODEL CREDIBILITY}

The model credibility is confirmed through several test referring to the guideline by Rhamandad and Sterman (2012) on "Reporting Guidelines for Simulation Based Research in the Social Sciences". The model structure is based on the literature pertinent to food systems, agriculture and economics. In this project, the corroboration between the model parameters and existing knowledge of the system can be considered sufficient to provide confidence in conceptual parameter validity. A detailed sensitivity analysis is listed in the model documentation (Refer to Appendix B).

\section{RESULT}

Figure 3 illustrates the impacts of four different policies under localizing food system on farmers' livelihood resilience. Farmer markets enable more farmers to develop entrepreneurship. Over time, it increases the products sold at farmer markets. Farmer markets also strengthen the seller-buyer relationship. A better relationship builds trust and increases market product demand through the word-of-mouth effect. Also, such trust is essential during shocks. When the product price increases, buyers would still buy from the farmers to support them during difficult times. Moreover, trusts increase food box delivery orders as support against food delivery competition from supermarkets.

Next, marketing for farmer market organization grows the number of members, leads to more farmers acquiring price negotiating power by selling products through food hub. More members also result in more products being sold through farmer markets. Lastly, farmers can act collectively in problem-solving through farmer organization instead of relying on external interventions. The following table outlines the result from the model simulation. The current model does not quantify resilience from all its components (see discussion section for explanation). The results are analyzed using both quantitative and qualitative methods.

(The model explores initiatives that could be implemented to address farmer livelihood issue. It is important to note that the numeric outcomes being simulated should not be thought of as accurate predictions or forecast).

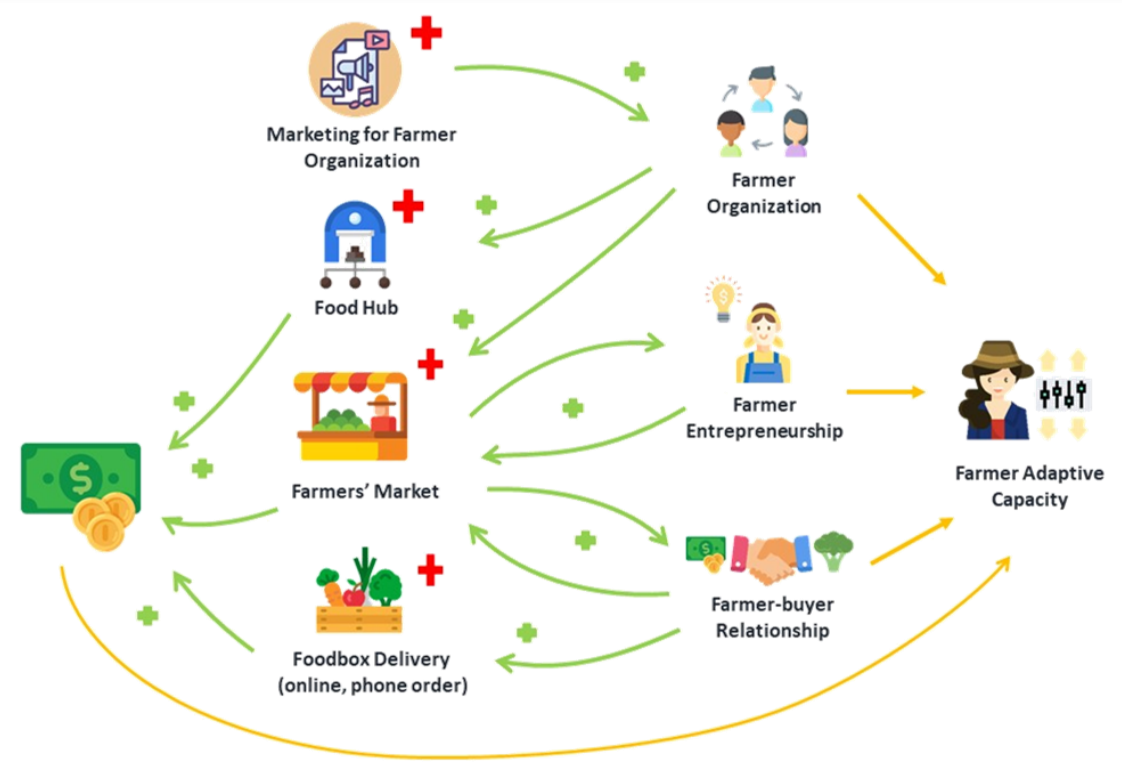

Figure 3. Impacts of recommended policies

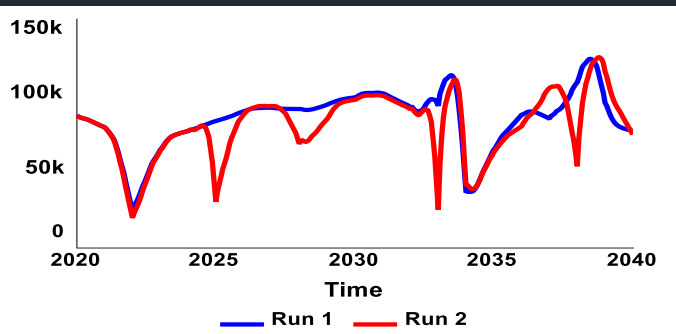

Run 1: Estimated SA Rain Precipitation from past historical data
Run 2: Estimated Rain Precipitation with severe climate disturbance 


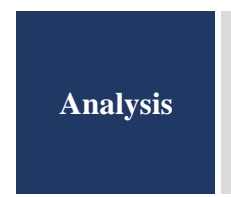

BAU: Products are sold through wholesalers and farmer market (9 farmer markets as of 2011)

The behavior of farmer income oscillates negatively at a higher amplitude in Run 2. Farmers earn lesser when severe climate disturbance disrupts crop production, and increases production and logistic cost. The shocks strengthen the price balancing feedback loop, and it weakens the direct wholesale and farmer market reinforcing feedback loops.

\begin{tabular}{|c|c|c|c|c|}
\hline \multicolumn{4}{|c|}{ Scenarios below are conducted with severe climate disturbance } \\
\hline \multirow{2}{*}{$\begin{array}{c}\text { Scenarios } \\
\text { Funding } \\
\text { one policies }\end{array}$} & $\begin{array}{c}\text { Run 1: } \\
\text { BAU }\end{array}$ & $\begin{array}{c}\text { Run 2: } \\
\text { Farmer market capacity } \\
\text { expansion }\end{array}$ & $\begin{array}{c}\text { Run 3: } \\
\text { Farmer market } \\
\text { organization marketing }\end{array}$ & $\begin{array}{c}\text { Run 4: } \\
\text { Setting up food hubs }\end{array}$ \\
\hline $\mathbf{1 . 5}$ million & 55900 & Farm Income per Farmer in 2040 (AUD/farmer/year) & $\mathbf{7 6 2 0 0}$ \\
\hline $\mathbf{3}$ million & 55900 & 60200 & 55900 & 76200 \\
\hline
\end{tabular}

The farmer market capacity expansion (Run 2) and setting up food hubs (Run 4), show a significant scale up the farmer income. Setting up a food hub gives a promising outcome as the farmer organization negotiated product price is higher than the usual wholesaler bulk price. More products from the vegetable farmers are channelled through food hub than farmer markets because funding is used to set up food hub, an inventory with facilities for vegetable storage.

On the other hand, farmer market capacity expansion is not as high as setting up food hub because farmer markets have different stalls that range from dairy, meat, vegetable, to cooked foods (are not included in this model). The model boundary limits to stalls that sell tomato, lettuce, and broccoli at farmer markets, as shown above. Hence, the result from farmer market capacity expansion is not as high as setting up food hub. Do note that the cumulative outcome from all stalls in farmer markets will be significant.

There is no difference observed in the result of marketing for farmer market organization. Increasing the number of members means more farmers want to sell at farmer markets. The current farmer markets that are already saturated with different farmer stalls (the capacity of farmer market is functioning at its maximum) or will become saturated very soon with the new members would not have any impact on farmer income unless the farmer market capacity is expanded for the new farmers to sell their products.

Setting up food box delivery is not part of one policy simulation because this service relies on food hub availability.

The difference between funding 1.5 million and 3 million is minimal for vegetable farmer income. Only farmer market capacity expansion gives a 3500 AUD increase in income (for instance, in 2040). The effort to strengthen the farmer market reinforcing loop is eventually constrained by the number of farmers available to sell at the markets.

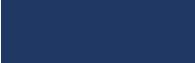

Scenarios

Funding

two policies

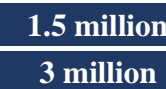

Scenarios

Funding

two policies

1.5 million

3 million

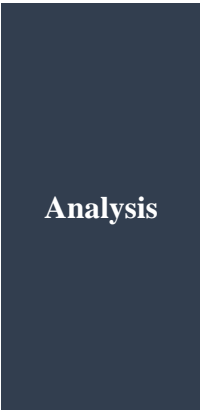

\section{Run 2:}

Run 1:

BAU

Farmer market capacity expansion

$+$

Farmer market organization marketing
Run 3:

Farmer market capacity expansion Setting up food hubs

\begin{tabular}{|c|c|c|}
\hline \multicolumn{3}{|c|}{ Farm Income per Farmer in 2040 (AUD/farmer/year) } \\
\hline 55900 & 60000 & 78200 \\
\hline 55900 & 63300 & 89400 \\
\hline $\begin{array}{c}\text { Run 1: } \\
\text { BAU }\end{array}$ & $\begin{array}{c}\text { Run 2: } \\
\text { Farmer market organization } \\
\text { marketing }+ \\
\text { Setting up food hubs }\end{array}$ & $\begin{array}{c}\text { Run 3: } \\
\text { Setting up food hubs }+ \\
\text { Setting up food box delivery }\end{array}$ \\
\hline \multicolumn{3}{|c|}{ Farm Income per Farmer in 2040 (AUD/farmer/year) } \\
\hline 55900 & 76200 & 89000 \\
\hline 55900 & 76200 & 89400 \\
\hline
\end{tabular}

Although farmer market capacity expansion and farmer market organization marketing policy contribute the most to components of resilience in farmer organization, entrepreneurship, seller-buyer relationship), it shows the slightest increase of income among the four simulations above.

Setting up food hubs and food box delivery shows the best outcome on income; however, this policy contributes the least to other components of building livelihood resilience (farmer organization, entrepreneurship, buyer-seller relationship).

If the local council has only 1.5 million AUD per year for funding and other resources constraint that allows only two policies implementation, a combination of farmer market capacity expansion and setting up food hubs policies gives the most favorable impacts on farmer income, entrepreneurship, seller-buyer relationship aspects of resilience. 


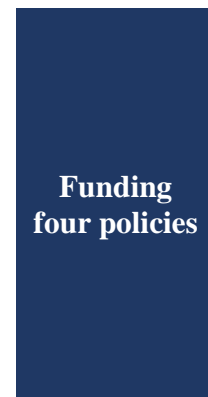

In 2040:

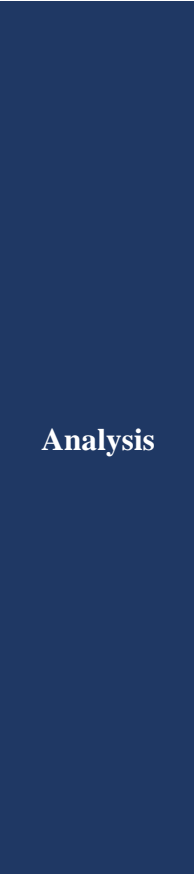

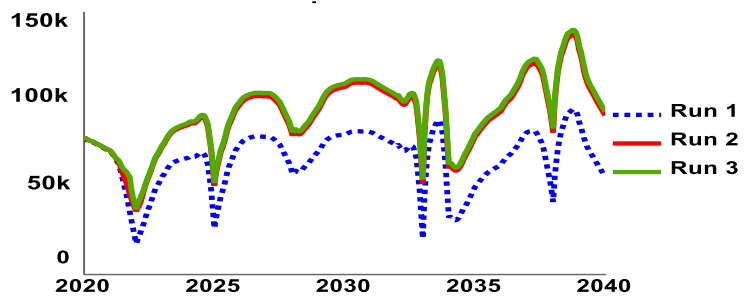

Run 1:

BAU

55900

Run 2:

Funding: 1.5 million AUD/year

91100
Run 3:

Funding: 3 million AUD/year

93300

This combination of farmer market capacity expansion, marketing for farmer organization, setting up food hubs, and food box delivery shows the best outcome among all the simulations. The interactions among various levels impact the effectiveness of these policies.

With the same 1.5 million AUD share among four policies implementation, with the farmer market operation cost taking a majority of the fund, $70 \%$. Again, expanding farmer market capacity is expensive, but it benefits farmers other than vegetable farmers. Also, its impact on resilience is significant. When the funding increases to 3 million AUD, the impact is minimal because most of the fund is used in farmer market operational costs. Besides, even if funding is plentiful to set up more food hubs, it is unrealistic that farmers will sell all products through farmer markets and food hub only within 20 years. It is assumed that farmers will still sell part of their products through the direct wholesaler loop. Hence, it is recommended to use the extra funding in other policies (see potential next steps below).

Although the combination of policies scales up the farm income the most, farmers still experience a similar magnitude of loss during shocks. The severe climate disturbance on crop lost and increased production cost is inevitable; hence, even after the policies are implemented, farmers will still experience similar impacts. However, they now experience a lesser loss compared to BAU. For instance, the farm income of Run 2 (with a combination of policies) in 2033 severe drought is 54500 AUD compared to BAU 20700 AUD. The farmers have income that is two and half times more than BAU income under a more resilient system. Also, when farmers earn more, they have more savings, and it provides resources for recovery aftershocks.

A more resilient system also means that income drops and rises at smaller, faster scales. This behavior is not observed in the policies simulation because the farm income does not include farm saving that they may have used during shocks. Besides, the model does not include short-term policy such as compensation for crop loss from either government or insurance. If such compensation or saving is channelled into farm income inflow (model structure), the result is expected to drop and rise at a smaller, faster scales during shocks.

\section{DISCUSSION AND CONCLUSION}

Localizing food system is seen as a recipe ailing communities to solve a wide range of social, economic, and health problems. Yet, Deller, Lamie, and Stickel (2017) study reveal the lack of literature that assesses impacts systematically, nor the data to provide the clear evidence to support the claims being made by many. The model addresses some of these concerns through a quantitative modelling simulation approach, a far more systematic, robust tool, in testing policies that potentially deliver greatest impacts than, relying on mental simulation or overpromising literature.

Local councils must explore the positive impacts of the proposed policies and the constraints or unintended consequences to avoid poor investment choices. The model includes constraints such as price, availability, capacity, and demand loops that portray real-world limitations. The simulation reveals certain policy or combination of policies deliver little or no impact, while a combination of all four policies give the best outcome on fostering resilience.

\section{The findings highlight three key messages:}

First, to improve the social environment in achieving better farmers' livelihood resilience, the local council should not rely on one or two policies. A diversity of responses/policies should be encouraged, not only from the government but also the farmers organization or other stakeholders. Channelling resources into one specific policy may backfire if the policy has unintended consequences or delivers minimal impact. For instance, if the local council funds all the money into farmer market capacity expansion, what if no farmer wants to sell at the market; what if the market only attracts particular types of consumers and does not have sufficient demand to sustain the newly open farmer markets. Besides, when most resources are devoted to one solution, reduces the incentive to invest in alternative solutions that could be inherently better. The model shows that building resilience needs to occur at multiple levels (immediate physical infrastructure/services, social relationships, and power relation), since the effectiveness of these policies is impacted by the interactions among various levels.

Second, resources are finite; local councils must find the balance in managing resources for immediate shocks coping capacity versus future adaptative capacity. A sudden major shift of resources might create policy resistance among the stakeholders. For instance, when climate disturbance is too severe for farmers to cope with, and if the 
farmer or the system has yet to develop adaptive capacity, the local council first needs to implement the immediate, short-term policies. However, such policies should only be used to buy time while working on more fundamental solutions, as described in Figure 1, to avoid fixes that fail.

Third, although the model shows the best outcome under the policies, translating these policies into implementation requires concerted efforts from all actors in the food system. Stakeholders should be invited to participate in group model building (GMB). GMB is a participatory method which engages various stakeholders to build collective visual models to comprehend complex problems. Causal loop diagrams (CLD) that are produced in GMB can appear unusual and complex initially. Nevertheless, CLD can often be co-created by novice participants (without in-depth system dynamics knowledge). Moreover, the identification of causal loops and leverage points for interventions contributes to shared views of the systems/problems amongst participants and a sense of achievement or ownership on the proposed policies. Such collective completion of a complex task builds consensus and commitment to decisions among participants with different attitudes. Moreover, this process resists the top-down approach, favoring knowledge co-created by multiple stakeholders instead. The findings from GMB should be then used to update the current model.

In addition to the GMB, the potential next steps include quantification of farmers' livelihood resilience and a policy for diversifying types of consumers for local food demand. The soft variable farmers' livelihood resilience is yet to be quantified in the model as the modelers need more time to build this model structure credibly. The model also has yet to include a policy in increasing consumer demand on local food. One of the reasons is that the stakeholders' inputs revealed an increased demand for local food, especially under the impact of COVID-19 movement restriction. Hence, resources are prioritized into building other structures in food system. However, there is a policy plan of diversifying types of consumers through food box delivery. Farmer markets tend to attract consumers that have time to purchase and cooking at home. However, stakeholders' inputs showed that many low-and middle-income families are not buying local fresh food not eating healthily. Hence, food box delivery can be used to target this group of consumers by reducing the first barrier, access to local product food (without going to farmer markets). Next, creating a reward system to encourage behavior change among the consumers who are used to quick and hyper-palatable processed food. For instance, through the food box delivery apps, create a campaign of "One for you, one for your neighbor" in low-cost housing areas. Such campaign not only avoids the possible stigmatization of "food baskets for poor people", but also improve the social relationship among the neighbors.

\section{ACKNOWLEDGMENTS}

This project was conducted under the System Dynamics course: Client-based Modeling project, in May 2021. Guidance from Professor Birgit Kopainsky, Brooke Wilkerson, and Ariella Helfgott is deeply appreciated.

Contributors: PSL had primary responsibility for final content. FÖ and PSL are main modelers. FÖ, KB, MS and VS were responsible mostly for model structure validation (triangulation primary, secondary data, and test).

\section{REFERENCES}

Deller, S. C., Lamie, D., \& Stickel, M. (2017). Local foods systems and community economic development. Community Development, 48(5), 612-638.

Forrester, Jay (1961). Industrial Dynamics. Cambridge, Massachusetts: M.I.T Press.

Government of South Australia. (2020). South Australian Government Climate Change Action Plan 2021-2025. Government of South Australia.

Herrera, H., \& Kopainsky, B. (2020). Using system dynamics to support a participatory assessment of resilience. Environment systems and decisions, 40(3), 342-355.

Kangogo, D., Dentoni, D., \& Bijman, J. (2020). Determinants of farm resilience to climate change: The role of farmer entrepreneurship and value chain collaborations. Sustainability, 12(3), 868.

King, C. A. (2008). Community resilience and contemporary agri-ecological systems: reconnecting people and food, and people with people. Systems Research and Behavioral Science: The Official Journal of the International Federation for Systems Research, 25(1), 111-124.

Rahmandad, H., \& Sterman, J. D. (2012). Reporting guidelines for simulation-based research in social sciences.

SURE Farm. (2021). Principles for a resilience enabling environment. https://www.surefarmproject.eu/wordpress/wpcontent/uploads/2021/02/SUREFARM-D6.3-Policy-Brief.pdf

\section{APPENDICES: APPENDIX A (CLD), APPENDIX B (SENSITIVITY TEST), AND APPENDIX C (DOCUMENTATION), APPENDIX D (MODEL)}

